\title{
A INFLUÊNCIA DO MARKETING VERDE NA DECISÂO DE COMPRA DO CONSUMIDOR
}

\author{
Luiz Carlos dos Santos ${ }^{1}$ \\ Roseli Costa ${ }^{2}$ \\ Mariana de Camargo ${ }^{3}$ \\ Mayara Pereira ${ }^{4}$ \\ Silene Fernandes Bicudo ${ }^{5}$
}

Resumo: No decorrer dos anos têm se notado as consequências que os hábitos humanos vêm causando a natureza, por conta disso, surgiu o chamado "Marketing Verde". Trata-se da campanha ecológica que a empresa faz e coloca em prática, visando amenizar o dano causado a natureza. É o meio usado para alcançar cada vez mais pessoas a fim de conscientizá-las, fazendo com que a preocupação com o planeta seja vista com maior atenção. Este trabalho tem como finalidade abordar este tema, e através de um questionário aplicado há um grupo de moradores da cidade de Campos do Jordão, ter um retorno de como as pessoas veem essa ferramenta, se conhecem seus produtos, qual a influencia na decisão de compra e se mudariam suas atitudes para melhorar o planeta que habitamos. O que pode se observar, foi que apesar da falta de conhecimento do assunto, muitos estão dispostos a se adaptar para contribuir com o meio ambiente.

Palavras-chave: Marketing Verde; Meio Ambiente; Consciência Ecológica.

\footnotetext{
1 Administração de Empresas/Univap, Brasil. E-mail: luizhott@hotmail.com.

2 Administração de Empresas/Univap, Brasil. E-mail: cherrymoremio@hotmail.com.

3 Administração de Empresas/Univap, Brasil. E-mail: mari.kmargo@hotmail.com.

${ }^{4}$ Administração de Empresas/Univap, Brasil. E-mail: maah.pereira0106@gmail.com.

${ }^{5}$ Administração de Empresas/Univap, Brasil. E-mail: silene@univap.br.
} 